\title{
ORALIA: HASTA HOY Y DESDE HOY
}

En abril de 1998 se celebró en la Universidad Complutense de Madrid el I Simposio Internacional de Análisis del Discurso; no fue este el primero, pero sí el más importante acontecimiento para la investigación y difusión de los estudios discursivos en el mundo hispánico.

No sabemos si realmente la diosa Ocasión era tan bella como la costumbre romana gustaba de representarla, ni creemos siquiera que fuera calva, habida cuenta de los largos mechones que aparecían alrededor de su frente; lo que sí es cierto es que por aquel mes de abril anduvo cerca de nosotros y permitió la coincidencia del inicio de Oralia con el simposio de la Complutense, en una de cuyas sesiones encontró acomodo su presentación. El preludio no pudo tener mejor cuna, y meses después (octubre de 1998) apareció el primer volumen. Hoy llegamos, tras veinte años de ilusión, a un momento importante para el futuro de la revista.

Quienes hemos participado en este proyecto estamos satisfechos con el recorrido; es justo y obligado reconocer, en primer lugar, el trabajo de los secretarios durante distintas fases de la revista, los doctores Bañón Hernández, tan implicado en su creación, Espejo Muriel y Muñío Valverde. La publicación siempre mantendrá una deuda con ellos; asimismo, la tiene con el esfuerzo y consejos de otros colegas y amigos: los doctores Narbona, Polo, Hidalgo, Briz, Pons, Placencia, etc.; también, con quienes han colaborado aportando su esfuerzo en forma de artículos, notas, reseñas e informes. Gracias a todos.

El carácter internacional de la revista se muestra en su difusión, en la composición de sus consejos y en el origen de sus colaboradores. En sus páginas, han publicado hispanistas de diferentes países: Alemania, Argentina, Australia, Bélgica, Canadá, Chile, Cuba, Estados Unidos, Francia, Holanda, Inglaterra, Italia, México, Suecia, Venezuela, etc. Hasta el presente, se han editado cinco volúmenes monográficos: volumen 4 (2001), dedicado a la cortesía; volumen 8 (2005), que se ocupó de los corpus orales; volumen 12 (2009), destinado al estudio del discurso político; vol. 16 (2013), que trató de argumentación y persuasión, y este vol. 20 (2017), que, como puede comprobar el lector, se dedica a discurso y salud. Han aparecido, además, seis obras monográficas. Oralia aparece referenciada en CIRC, Dialnet, DULCINEA, ISOC, Latindex, L-DICE (CINDOC), Linguistic Abstracts Online 
(LABO), Matriu d'Informació per a la Avaluación de Revistes (MIAR), MLA International Bibliography, Portal del Hispanismo (Instituto Cervantes), Revistas Españolas de Ciencias Sociales y Humanas (RESH), Scopus, Ulrich's Global Serials Directory, WordlCat, Zeitschriftendatenbank (ZDB).

Es el hasta hoy de Oralia, que, aun sin que consideremos que sea poco o insuficiente, quisiéramos que fuera mejor. Y con esta idea, nos complace anunciar que desde el próximo número iniciaremos no tanto una nueva etapa cuanto una serie de novedades con que renovar, pensamos, la revista. Así, el volumen 21 traerá no solo el cambio de dirección, que recaerá en el Dr. Bañón Hernández, sino también la renovación del secretariado con la presencia de los doctores López Cruces y López Muñoz, junto a la Dra. Espejo Muriel. La revista, que va a contar con la ayuda del Departamento de Filología y el Vicerrectorado de Investigación de la Universidad de Almería, así como de su Centro de Comunicación y Sociedad (CySOC), dejará de ser anual para pasar a ser semestral; cada volumen se publicará en dos tomos, que aparecerán en los meses de junio y diciembre de cada año.

Luis CoRTÉs Rodríguez

José Jesús de Bustos Tovar 